\title{
The Role of Pediatrics in Medical Toxicology: a Fellow's Perspective
}

\author{
Jennifer A. Ross ${ }^{1}[$ \\ Received: 24 June 2021 / Accepted: 28 June 2021 / Published online: 4 August 2021 \\ (c) American College of Medical Toxicology 2021
}

Keywords Commentary $\cdot$ Pediatric toxicology $\cdot$ JMT fellow-in-training editor

In the 1950s, unintentional pediatric poisonings were a leading cause of morbidity, and resources to guide healthcare providers in treating poisoned patients were limited [1]. To fulfill the need for a centralized source of information on toxic substances, pediatricians established the first poison center in Chicago in 1953 [2, 3]. Since that time, pediatricians have continued to play an important role in the development and evolution of poison centers. In a field where an ingestion of a single pill can kill a child [4], the pharmacologic expertise of pediatric toxicologists plays an important role in medication safety and public health poison prevention efforts. Major milestones in poison prevention include the designation of a National Poison Prevention Week in 1961, the passing of the Poison Prevention Packaging Act in 1970, and the establishment of nationwide toll-free access to poison centers in 2001 [5, 6]. Even with these improvements in legislation, pediatric exposures remain the leading reason for poison center calls, with children younger than 6 years of age constituting $42.8 \%$ of all exposures in 2019 [7].

The epidemiology of pediatric exposures is constantly evolving, with new products continually introduced to the market and social media playing a role in recent dangerous trends among youth. The sudden popularity of vaping introduced new risks to adolescents and young adults, evidenced by the youth vaping epidemic and the morbidity associated with electronic cigarette, or vaping, product use-associated lung injury (EVALI) [8]. Cannabis edibles pose a serious threat to young children who mistake these lookalike products for candy, and exposures reported to poison centers have increased over recent years [9]. New social media

Supervising Editor: Mark B. Mycyk, MD.

Jennifer A. Ross

jennyross513@gmail.com

1 Division of Medical Toxicology, University of Virginia, 1222 Jefferson Park Ave, 4th floor, PO Box 800774, Charlottesville, VA 22908, USA challenges continue to emerge and are often undertaken by youth ignorant of the potentially dangerous consequences, with examples including the "Benadryl Challenge," the "Tide Pod Challenge," the "Cinnamon Challenge," and the "Hot Pepper Challenge" [10-14]. From 2018 to 2019, there was an overall increase of $16.3 \%$ in exposure-related fatalities in children younger than 20 years old [7].

With the continued high prevalence of pediatric poisonings and the risks of associated morbidities, there is ongoing need for the expertise of pediatric toxicologists. However, currently, $93 \%$ of medical toxicology divisions are housed within emergency medicine departments [15]. The focal shift from pediatrics to emergency medicine dates to 1968 when the American Academy of Clinical Toxicology and the American College of Emergency Physicians were founded, and the focus of toxicology broadened to include patients of all ages [16]. This led to a greater prevalence of medical toxicologists from the field of emergency medicine and the general consideration of medical toxicology as an emergency medicine subspecialty. Per a survey in $2000,68 \%$ of fellowship-trained toxicologists were emergency medicine certified [17], and in 2018, 90\% of medical toxicology fellows were emergency medicine trained [18].

Training in medical toxicology requires completion of a 2-year fellowship program focused on the management of poisoned and envenomated patients [19]. Trainees completing their residency in multiple different specialties, including pediatrics, are eligible to apply for this fellowship, but the application process is based in the National Residency Matching Program's Emergency Medicine Match [20]. As of 2021, there are currently 28 medical toxicology fellowship programs, of which $21(75 \%)$ report accepting applications from pediatricians [15]. Even so, only 10 (36\%) medical toxicology fellowships have trained a fellow from a pediatrics background in the past 5 years [15] and applicants report difficulties in finding programs that accept pediatrics-trained applicants [18]. As a current pediatrics-trained medical toxicology fellow, I 
encountered obstacles when applying for a toxicology fellowship position. In addition to toxicology-related service time, $20(71 \%)$ programs require their fellows to complete additional non-toxicology-related service time in order to fund their fellowship position [15]. These work duties are typically fulfilled by completing shifts in the emergency department, since this is the home department for most toxicology fellowship programs. While programs were open to the idea of training me, the logistics of how I would fulfill these additional work requirements were unclear, especially in programs that had never previously matched a pediatrics trainee. Additionally, I was the first from my pediatric residency to apply for a medical toxicology fellowship and I lacked a pediatric toxicology mentor to guide me through the application process.

Pediatricians can be assets to the toxicology team, so it is important that medical toxicology programs successfully recruit fellows from pediatrics. I suspect that the scarcity of current pediatrics-trained medical toxicologists can be traced back to pediatric residency, where there is often a gap in the education, clinical exposure, and recruitment opportunities afforded to pediatric residents. Exposure to toxicology seems largely provided only to those in emergency medicine training. Emergency medicine residents work directly with board-certified toxicologists and the majority of emergency medicine trainees are offered a toxicology rotation during their residency [21]. Unfortunately, many pediatric hospitals do not have access to a pediatric toxicologist, a poison control center directly affiliated with the hospital, nor a toxicology rotation offered to trainees. For pediatric residents, exposure to toxicology cases might be limited to infrequent emergency department shifts or the intermittent toxicologic patient requiring hospital admission. During my residency, I used an elective month to complete an away rotation in toxicology, but not everyone has this opportunity (especially during times of COVID-19 when away rotations were limited). By default, residents who work with toxicologists and study on toxicology rotations will be most likely to continue on a toxicology path. Increased exposure to toxicology during pediatric residency will likely directly correlate with an increase in interested fellowship applicants.

Toxicologists need to be more involved in pediatrics so that more pediatricians will be involved in toxicology. The relatively small pediatric toxicology community can harness the power of virtual teaching to maximize outreach and fill gaps in training programs without access to pediatric toxicologists. As a community, toxicologists can develop a database of virtual curricula, such as case-based scenarios, online resources, and recommendations for mentorship, that can be provided to interested trainees and programs. Efforts must be made to establish formal toxicology curricula in pediatric training programs so that pediatricians recognize the benefit of seeking out toxicologist expertise. Additionally, while toxicology fellowship programs report that they accept applicants from pediatrics, preventive medicine, and various other fields of training [15, 18], there are rarely recruitment strategies directed toward these residencies. In an emergency medicine dominated field, recruitment is innately directed to emergency medicine residents. I propose that toxicology fellowship programs expand recruitment strategies to target pediatrics programs and highlight career opportunities for pediatricians with toxicology training. National pediatric organizations should establish toxicology interest sections, and blogs and webinars from these organizations should introduce toxicology as a potential subspecialty career option. These recruitment efforts will require participation from established pediatric toxicologists, who can provide firsthand experience as to how toxicology training benefits pediatricians and describe various career options. As I become an established physician, I look forward to sharing my career path with trainees.

On a typical day, a toxicologist must play the role of pediatrician, emergency physician, critical care specialist, addiction medicine physician, and wilderness medicine expert. This herein is the beauty of toxicology: the field's necessary integration of numerous medical disciplines. It thus intuitively seems beneficial that toxicologists should come from a variety of medical backgrounds. Specifically, in order to successfully decrease childhood poisonings, we as toxicologists must strive to increase the pediatric toxicology workforce. There are systemic issues that will require time to change, but in the interim, there are actions that can be taken on both an individual and program level to make the field of toxicology more inclusive of various training backgrounds. It is critical that pediatric trainees are provided with increased exposure to and education about medical toxicology. Current pediatric toxicologists, medical toxicology fellowship program directors, and toxicology specialists of all backgrounds can work together to ensure that pediatricians have equal access to and opportunity for toxicology training. Through increased clinical exposure and enhanced recruitment strategies, medical toxicology can be reestablished as a pediatric subspecialty. The field of toxicology is in a unique position to address the significant public health and mental health crises of today's society, and it is imperative that we enable and encourage interested applicants from diverse medical training backgrounds, including pediatrics, to apply to toxicology fellowship.

Acknowledgements The author would like to thank Dr. Katherine O'Donnell and Dr. Leslie Applegate for their assistance with this commentary.

\section{Declarations}

Conflicts of Interest None

Sources of Funding None 


\section{References}

1. Sue MK, Hoffman RS. Poison control centers and poison epidemiology. In: Nelson LS, Howland MA, Lewin NA, Smith SW, Goldfrank LR, Hoffman RS, editors. 11th ed. Goldfrank's toxicologic emergencies. New York: McGraw-Hill Education; 2019. p. 1789-96.

2. Scherz RG, Robertson WO. The history of poison control centers in the United States. Clin Toxicol. 1978;12(3):291-6.

3. Wyckoff AS. AAP had hand in first poison control center. AAP News. 2013;34(10):45.

4. Eldridge D, Mutter K, Holstege C, Pauze D, Sharieff G. An evidence-based review of single pills and swallows that can kill a child. Pediatr Emerg Med Pract. 2010;7(3):1-14.

5. Schwartz L. Poison prevention and education. In: Nelson LS, Howland MA, Lewin NA, Smith SW, Goldfrank LR, Hoffman RS, editors. Goldfrank's toxicologic emergencies. 11th ed. New York: McGraw-Hill Education; 2019. p. 1782-8.

6. Woolf AD, Karnes DK, Kirrane BM. Preserving the United States's poison control system. Clin Toxicol. 2011;49:284-6.

7. Gummin DD, Mowry JB, Beuhler MC, Spyker DA, Brooks DE, Dibert KW, Rivers LJ, Pham NPT, Ryan ML. 2019 Annual Report of the American Association of Poison Control Centers' National Poison Data System (NPDS): 37th Annual Report. Clin Toxicol. 2020;58(12):1360-541.

8. Sadreameli SC, Mogayzel PJ. Curbing youth e-cigarette use must remain a priority. Pediatrics. 2020;146(1):e20200902.

9. Whitehill JM, Dilley JA, Brooks-Russell A, Terpak L, Graves JM. Edible cannabis exposures among children: 2017-2019. Pediatrics. 2021;147(4):e2020019893.

10. Brady KB. 'Benadryl Challenge': what pediatricians need to know. In AAP News. 2020. https://www.aappublications.org/ news/2020/11/09/focusbenadryl110920. Accessed 17 May 2021.

11. Pirani F. Are people really eating Tide Pods? Doctors warn parents about dangerous 'Tide Pod Challenge'. In The Atlanta Journal-Constitution. 2018. https://www.ajc.com/news/national/ are-people-really-eating-tide-pods-doctors-warn-parents-aboutdangerous-tide-pod-challenge/fgGxrYa6z5pAGuFoAJXpDI/. Accessed 17 May 2021.

12. Grant-Alfieri A, Schaechter J, Lipshultz SE. Ingesting and aspirating dry cinnamon by children and adolescents: the "cinnamon challenge." Pediatrics. 2013;131(5):833-5.
13. Elgersma C. 13 online challenges your kid already knows about. Common Sense Media. 2019. https://www.commonsensemedia. org/blog/viral-youtube-challenges-internet-stunts-popular-withkid. Accessed 17 May 2021.

14. Kriegel ER, Lazarevic B, Athanasian CE, Milanaik RL. TikTok, tide pods, and Tiger King: health implications of trends taking over pediatric populations. Curr Opin Pediatr. 2021;33(1):170-7.

15. American College of Medical Toxicology. Medical Toxicology Fellowship Programs 2021. 2021. https://www.acmt.net/_Library/ Fellowship_Programs/MT_Fellowship_Programs_Grid.pdf. Accessed 17 May 2021.

16. Institute of Medicine (US) Committee on poison prevention and control. Chapter 4: Historical context of poison. In: Forging a Poison Prevention and Control System. Washington DC: National Academies Press. 2004;80-105. https://www.ncbi.nlm.nih.gov/ books/NBK215785/. Accessed 17 May 2021.

17. Wax PM, Wax P, Donovan JW. Fellowship training in medical toxicology: characteristics, perceptions, and career impact. J Toxicol Clin Toxicol. 2000;38(6):637-42.

18 Kao L, Pizon A, and On Behalf of the ACMT Fellowship Directors Committee. Medical Toxicology Fellowship Training Is Available to Applicants from Many Specialties. J Med Toxicol. 2018;14(3):177-8.

19. American College of Medical Toxicology. About Medical Toxicology. 2021. https://www.acmt.net/overview.html. Accessed 17 May 2021.

20. National Residency Matching Program. Emergency Medicine Match. 2021. https://www.nrmp.org/fellowships/emergencymedicine-match/. Accessed 14 May 2021.

21. Laes R, Katzung KG, Hegarty C, Stellpflug SJ. Toxicology education in emergency medicine: an assessment and pilot study. Toxicol Commun. 2019;3(1):1-6.

Publisher's Note Springer Nature remains neutral with regard to jurisdictional claims in published maps and institutional affiliations. 